\title{
Study on the Decline Analysis of Oil Well Stimulation Rule Based on Matlab-m
}

\author{
Xie Congjiao, Guan Zhenliang, Luo Guoping, Zhou Hong \\ Key Laboratory of Tectonics and Petroleum Resources of Ministry of Education, China University of Geosciences, Wuhan, China
}

Email address:

cxie2004@cug.edu.cn (Xie Congjiao)

\section{To cite this article:}

Xie Congjiao, Guan Zhenliang, Luo Guoping, Zhou Hong. Study on the Decline Analysis of Oil Well Stimulation Rule Based on Matlab-m. American Journal of Applied Mathematics. Vol. 3, No. 4, 2015, pp. 174-178. doi: 10.11648/j.ajam.20150304.12

\begin{abstract}
Well Stimulation and machinery extraction are two main methods which the engineer of oil production and related industry used to increase production. The purpose is to enhance the oil field final recovery ratio though speeds up the production rate of the petroleum fluid, especially for old oil field development. A set of methods which be suitable for the high water content maturing field about predicting output of well stimulation used in Xiaermen oilfield and providing the foundation of the oil field natural decline regular pattern. Then, a decline-analysis model is derived based on reservoir characteristic parameters and used to analyze natural decline rates for the Xiaermen oilfield developed by waterflooding. Formation factor and remaining oil saturation are included in this model, which reveals non-linear relationships between natural decline rates and the production time. We applied the model to the oil-production data from different blocks in the Xiaermen oilfield and found non-linear relationships between natural decline rates and production time as foreseen by the model, especially at the high water cut period. The results showed that the analytical model could match the natural decline rate data satisfactorily. It was also found there are non-linear relationships between oil incrementals for water flooding step stimulation and step time which different laws with permeability, net pay, and remaining oil saturation and structure place of reservoir in limit period. Decline analysis can be used to predict different oil wells production nature decline rule. Furthermore, we made computer programming in Matlab-m language to calculate the natural decline rate with any time, which made it much easier and practical to predict the future decline rate. Finally, the analytical model was compared with conventional models.
\end{abstract}

Keywords: Matlab-m, Decline Analysis, Model

\section{Introduction}

The Xiaermen oilfield lies in Biyang County, Henan Province. It is surrounded by a large fault on the south and east sides to the west of Biyang Sag ${ }^{[1]}$, Nanxiang Basin.It was discovered in 1978 and started to develop by water flooding in 1990. The water cut (Oil well produced fluid quality percentage of the water ) is nearly $98 \%$ with a high decline rate of $24 \%$ by the end of 2013 (see Table 1).

Table 1. Xiaermen oilfield production history during 1990 and 2013.

\begin{tabular}{lll}
\hline Time & Actual decline rate (Di, \%) & Watercut (fw, \%) \\
\hline 1990 & 20.0 & 87.0 \\
1991 & 22.0 & 87.5 \\
1992 & 23.9 & 87.9 \\
1993 & 24.7 & 88.4 \\
1994 & 24.1 & 88.8 \\
1995 & 22.8 & 89.3 \\
1996 & 21.2 & 89.7 \\
\hline
\end{tabular}

\begin{tabular}{lll}
\hline Time & Actual decline rate (Di, \%) & Watercut (fw, \%) \\
\hline 1997 & 19.5 & 90.2 \\
1998 & 17.7 & 90.6 \\
1999 & 15.9 & 91.1 \\
2000 & 14.3 & 91.5 \\
2001 & 12.8 & 92.0 \\
2002 & 11.4 & 92.4 \\
2003 & 10.1 & 92.9 \\
2004 & 9.0 & 93.3 \\
2005 & 7.9 & 93.8 \\
2006 & 7.0 & 94.2 \\
2007 & 6.2 & 94.7 \\
2008 & 5.5 & 95.1 \\
2009 & 4.8 & 95.6 \\
2010 & 4.2 & 96.0 \\
2011 & 3.7 & 96.5 \\
2012 & 3.3 & 96.9 \\
2013 & 2.8 & 97.8 \\
\hline
\end{tabular}

Multiple techniques are incorporated and integrated, i.e. Monte Carlo simulation, experimental design and advanced decline analysis, in order to enhance credibility with more 
objectives and to become more applicable for Xiaermen oilfield. Many methods have been developed in the latest decades. One common practice is decline-curve-analysis. There have been a great number of papers on this subject ${ }^{[2-4]}$. This paper presents a new model called LL-model to predict decline rate using integration and analyses of sub-surface information and dynamic data.

Most of the existing decline-curve-analysis techniques are based on the empirical Arps equations ${ }^{[4]}$ : exponential, hyperbolic, and harmonic. It is difficult to judge which equation the reservoir will follow. On the other hand, these type declines have their limitations. For example, the exponential decline curve tends to underestimate reserves and production rates; the harmonic decline curve has a tendency to overpredict the reservoir performance ${ }^{[2-4]}$. In some cases, production-decline data does not follow any models and just crosses over these decline curves. So, estimating the natural decline rate has been a challenge for many years.

Many experts have attempted to interpret the empirical Arpsequations or to provide some theoretical basis in specific cases.It seems that few of new models have consolidated theory behind. As Raghavan ${ }^{[5]}$ pointed out in 1993, "Until the 1970s, decline-curve analysis was considered to be a convenient empiricalprocedure for analyzing performance; no particular significancewas to be attributed to the values of $D_{i}$ and $b$. To an extent, this isstill true even today." This may be the case still, even thoughanother 10 years have passed.

This paper focused on advanced decline analysis using integration and analyses of sub-surface information and well performance data, and combined static (geological) and dynamic flow models to predict reservoir performance. There is more here than just replacing the modeling process with a function.

\section{Methodology}

The Arps decline-curve-analysis approach was proposed nearly60 years ago. However, a great number of studies on production decline analysis are still based on this empirical method.Many published papers have tried to interpret the Arps declineequation theoretically ${ }^{[6-7]}$. The empirical Arps decline equation isused to represent the relationship between production rate and timefor oil/gas wells during the pseudosteady-state period and is shownas follows:

$$
q(t)=\frac{q_{i}}{\left(1+n D_{i} t\right)^{1 / n}}
$$

Where $\mathrm{q}(\mathrm{t})$ is the oil production rate at time $\mathrm{t}$ and $\mathrm{q}_{\mathrm{i}}$ is the initialoil production rate; $\mathrm{n}$ and $\mathrm{D}_{\mathrm{i}}$ are two constants.

Equ. 1 can become two special cases when $n$ equals to 0 or 1.

$\mathrm{n}=0$ represents an exponential decline in oil/gas production, which is expressedas follows:

$$
q(t)=q_{i} e^{-D_{i} t}
$$

$\mathrm{n}=1$ suggests a harmonic decline in oil/gas production, which can beexpressed as follows:

$$
q(t)=\frac{q_{i}}{\left(1+D_{i} t\right)}
$$

Any of other $\mathrm{b}$ values between 0 and 1 indicates $\mathrm{a}$ hyperbolic decline in oil/gas production.

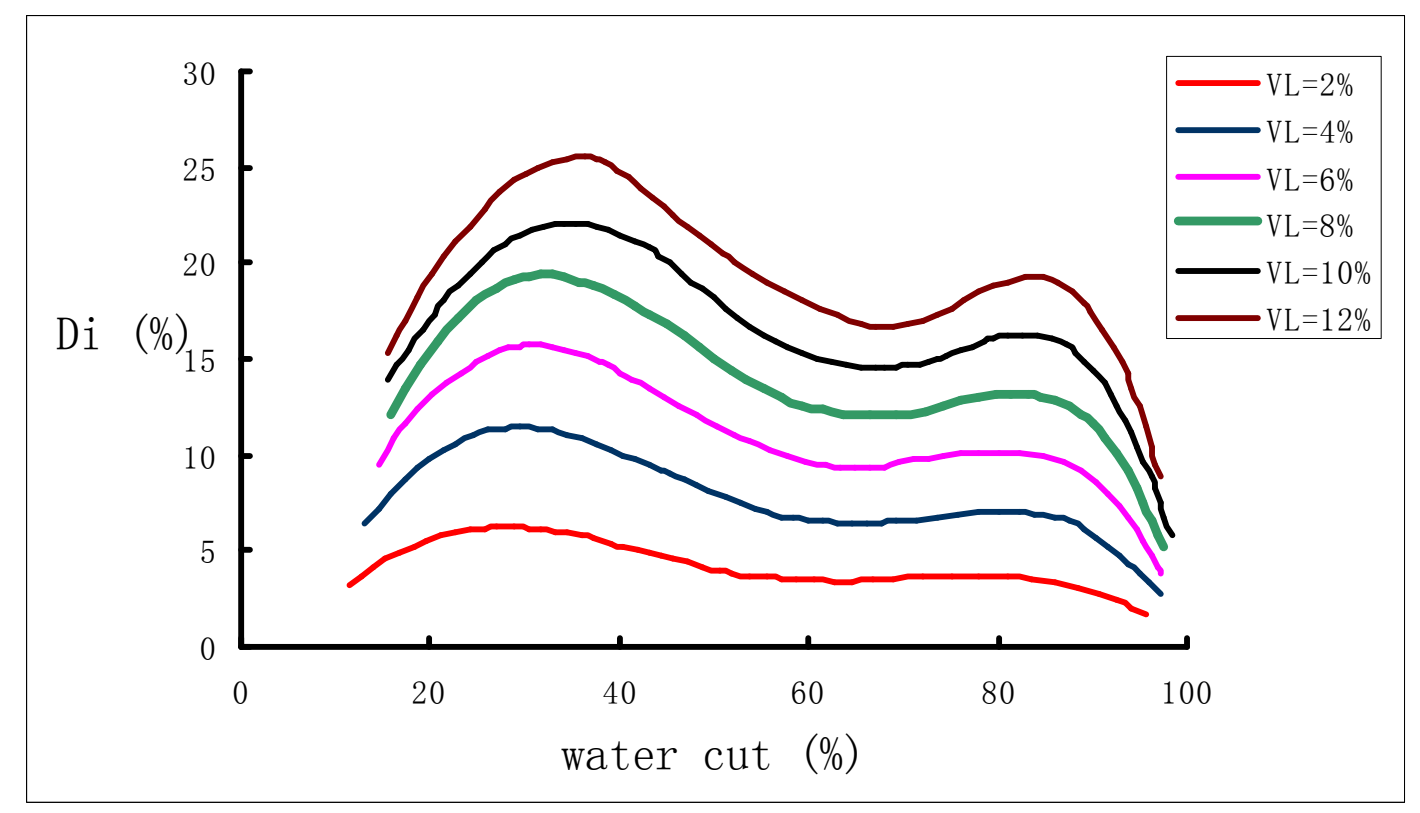

Fig. 1. Typical decline rate curves (decline rate vs water cut) in different VL in Xiaermenoilfield. 
phase. The empirical Arps decline equationswere employed for a long time by different VL (Liquid production rate) with water cut in Xiaermenoilfield (Fig.1). As can be seen in Fig.1, the curves (Di vs water cut) are shaped like a set of saddles in different liquid production rates. The saddle shape enables Di to decline quickly during high water cut periods (Fig.1). On the contrary, the decline rate is relatively slow in the filed after water cut higher than 90 percent.

Xie and LL developed an analytical model called LLmodel to predict decline rate with time for high water cut periods. The model is expressed as follows:

$$
D_{\mathrm{i}}=D_{0}+a t^{b} e^{-c t}
$$

Where $\mathrm{Di}$ is the decline rate at time $t \cdot \mathrm{D}_{0}$ is the initial decline rate by the year when the production starts to decline. The values of the three contents, $\mathrm{a}, \mathrm{b}$ and $\mathrm{c}$ are associated with the formation factors: $\mathrm{Kh}$ (product of formation permeability and net pay), porosity $(\varphi)$ and remaining oil saturation (Soi), respectively (Table 2). For this, Equ.4 was solved in terms of decline rate and time. Using the reservoir properties in the the Xiaermen oilfield, Equ. 4 could become the following equation:

$$
\mathrm{D}_{i}=4.5-4.375 t^{0.1837} e^{-0.1163 t}
$$

Table 2. The relationships between Di and oil reservoir parameters.

\begin{tabular}{lllllll}
\hline Type & Kh & a & b & p & c \\
\hline I & $>10$ & $-4.529 \sim-4.22$ & $0.1376 \sim 0.2298$ & $>21 \%$ & $0.1089 \sim 0.1237$ \\
II & $6-10$ & $-4.245 \sim-3.81$ & $0.1777 \sim 0.3238$ & $19-21 \%$ & $0.1277 \sim 0.1518$ \\
III & $1-6$ & $-3.893 \sim-3.17$ & $0.2505 \sim 0.5387$ & $<19 \%$ & $0.1623 \sim 0.2123$ \\
\hline
\end{tabular}

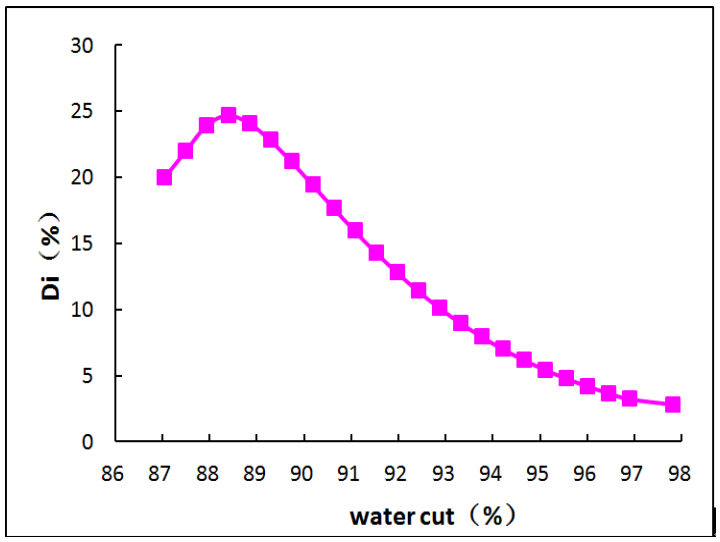

Fig. 2. Decline rate curve based on LL-model in Xiaermen oilfield.

Equ. 5 demonstrates the non-linear relationships between the natural decline rates and the production time. When we replace time $t$ with water cut in Equ. 4, the curves could become the forms shown in Fig.2, which shows that the LLmodel predicts decline rate during high water cur periods in the oilfield.

The curve in Fig. 3 indicates that the decline rate would become moderate when water cut is higher than 96.2 percent till the economic limit in the Xiaermen oilfield.

A series of similar curves can be derived from Table 2 with different $\mathrm{a}, \mathrm{b}$ and $\mathrm{c}$ within the range $\mathrm{a}, \mathrm{b}$ and $\mathrm{c}$ (shown in Table 2) Fig.4 shows three types of decline curves. Which are practically used in Xiaermen oilfield? Type III is the best one with high $\mathrm{Kh}(\mathrm{Kh}>10)$, high porosity $(\varphi>21 \%)$; Type I is the worst one with low $\mathrm{Kh}(6>\mathrm{Kh}>1)$, low porosity $(\varphi<19 \%)$; Type II is the middle case between type I and type III. The built relationships between a andKh, $\mathrm{b}$ and $\varphi$, $\mathrm{c}$ and Soi need to be investigated further. But one thing can be proved that the better the oil reservoir quality is, the slower oil production rate declines (Fig.3).

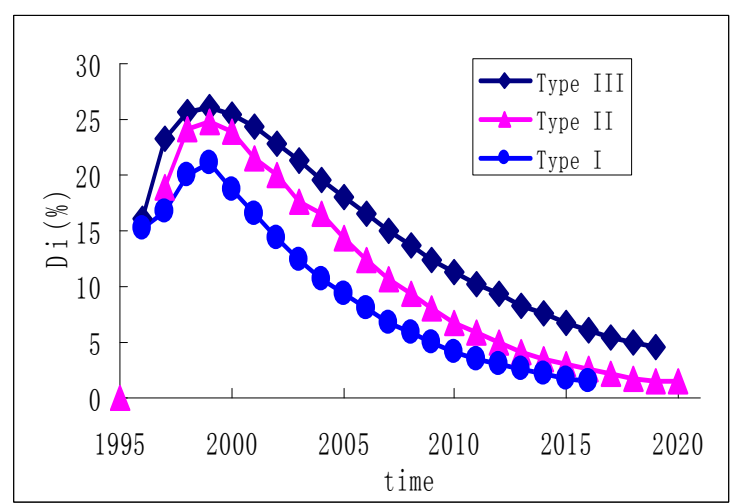

Fig. 3. Different decline rate curves with three sets of oil reservoir properties.

Fig. 4 is the Lognormal-model used to predict production rate $\mathrm{Q}$. This curve is very similar to the LL-model but the production ratefaster than the LL-curve.

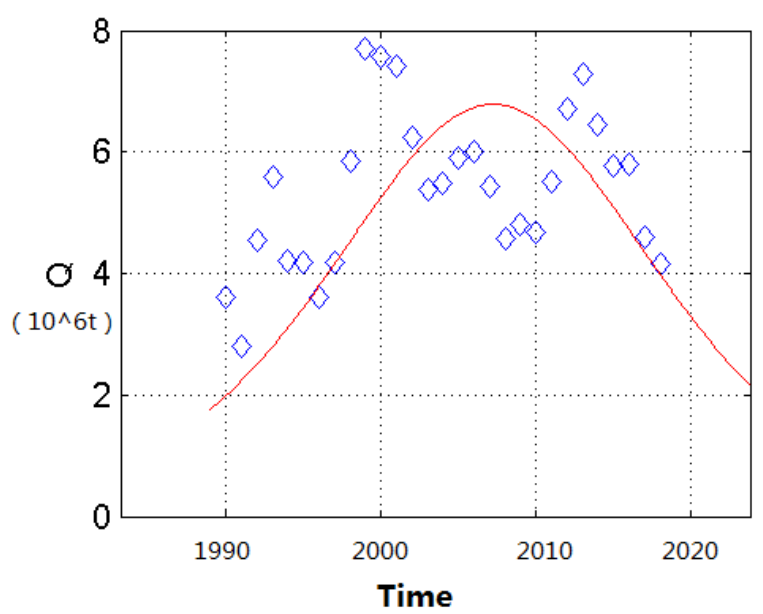

Fig. 4. Decline rate curve based on Lognormal-model in Xiaermen oilfield. 
To validate the LL-model, we computed the predicted decline rates in 2007 and 2008 using Equ. 5 and compared with the field observed decline rates. Table 3 shows the relative errors.

Table 3. Comparasions of Di between actual and predicted decline rate of Xiaermen oil field.

\begin{tabular}{|c|c|c|c|c|c|c|c|c|}
\hline \multirow{2}{*}{ Time } & \multicolumn{4}{|l|}{2007} & \multicolumn{4}{|l|}{2008} \\
\hline & actual & Predicted & Absolute value & Relative error & Actual & Predicted & Absolute value & Relative error \\
\hline $\mathrm{Di}$ & 6.2 & 6.48 & 0.28 & $4.5 \%$ & 5.46 & 5.68 & 0.22 & $4.0 \%$ \\
\hline
\end{tabular}

Table 3 shows that the relative errors are quite low with an average of 1.85 percent. We do believe the relative error would be no more than 1 percent with the time past1. By 2020 , the relative error could be no more than 0.1 percent. By then, water cut would be growing significantly, up to 99.6 percent.

We also developed programming in Matlab-m language to calculate natural decline rate with any time (Fig. 5). In Fig.5 we use NDi instead of Di to fit the curve in order to display when water cut is close to the limited water cut. NDi is the sum of every Di when the program was run. This program may predict future decline rates. More, the analytical model was benchmarked with some conventional models.

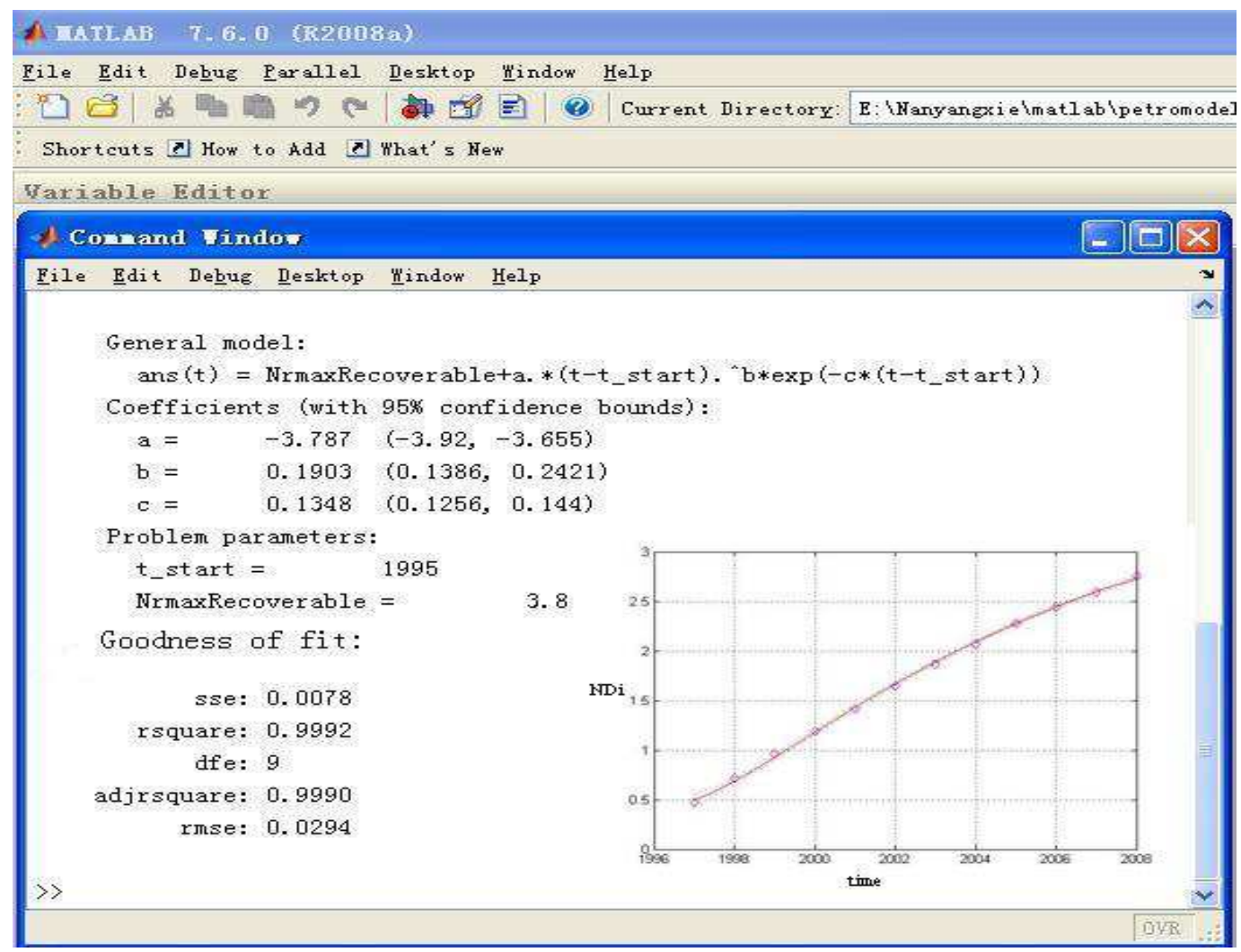

Fig. 5. Matlab programming and run results with LL-model.

\section{Results and Discussion}

A large number of decline rates have been carried out and the results are presented in Table 4 . In addition, the predicted decline rates are found for next 10 years in Fig. 4 as well.

Table 4. Xiaermen oilfield predicted production data from 2013 to 2020.

\begin{tabular}{lll}
\hline Time & Predicted decline rate (Di, \%) & Watercut (fw, \%) \\
\hline 2013 & 2.85 & 97.8 \\
2014 & 2.55 & 98.1 \\
2015 & 2.48 & 98.5 \\
2016 & 1.96 & 98.9 \\
2017 & 1.78 & 99.1 \\
2018 & 1.69 & 99.3 \\
2019 & 1.23 & 99.4 \\
2020 & 1.09 & 99.6 \\
\hline
\end{tabular}

In addition, we observed that Type I corresponding to high reservoir quality (high $\mathrm{Kh}, \varphi$ and Soi) in Fig. 4 is consistent with the Arps theory. Further work is needed to allow a quantitative analysis of the observed phenomena and investigate the relationships, such as between $\mathrm{a}$ andKh, $\mathrm{b}$ and $\varphi$, c and Soi.

\section{Conclusions}

1) It is a non-linear relationship between oil incremental by water flooding step stimulation and step time which different laws with permeability, net pay, oil saturation and structure place of reservoir in limit period.

2) Decline analysis can be used to predict different oil 
wells production by nature decline rule.

3) The new developed LL-model is applicable to forecast decline rate in the Xiaermen oilfield.

\section{Nomenclature}

$n_{-}$constant
$a_{-}$constant
$b_{-}$constant
$c_{-}$constant

Do_the initial decline rate by the year when the production is decreasing, $\%$

$\mathrm{Di}$ the decline rate at time t, $\%$

$t$ production time, $\mathrm{t}$

$K_{-}$absolute permeability, $\mathrm{mD}$

$h$ net pay, L

$\varphi$ _ porosity, \%

Soi_remaining oil saturation, $\%$

$f w_{-}$water cut, $\%$

\section{Acknowledgments}

We are grateful to Exploration and Development Research Institute of SINOPEC Henan oil field for providing us with the Xiaermen oilfield data used in this work and financial supports. This research was conducted partially with financial support from the China University of Geosciences Program under grant KH136311, and with support from the faculty of earth sciences of CUG, these contributions are gratefully acknowledged.

\section{References}

[1] Xie, C.j. Guan, Z.L. Blunt, M.J, Zhou, H, "Numerical simulation for oil Reservoir after cross-linked Polymer Flooding", Journal of Canadian Petroleum Technology, April 2009, Volume 48, No. 4: 37-41

[2] Agarwal, R.G. et al.: "Analyzing Well Production Data Using Combined-Type-Curve and Decline-Curve Analysis Concepts," SPEREE (October 1999) 478.

[3] Agbi, B. and Ng, M.C.: "A Numerical Solution to TwoParameter Representation of Production Decline Curve Analysis," paper SPE 16505 presented at the 1987 SPE Petroleum Industry Applications of Microcomputers, Montgomery, Texas, 23-26 June.

[4] Arps, J.J.: “Analysis of Decline Curves,” Trans., AIME (1945) $160,228-247$.

[5] Raghavan, R.: Well Test Analysis, PTR Prentice Hall, New Jersey (1993).
[6] Chen, Q.Y, Xie, C.J and Li X.Y. "The Study for the History of Well Stimulation for Xiaermen Oilfield He 3 Formation VII Group Reservoir", Petroleum geology and engineering, 2009, Vol.23, No.5

[7] Hu, J.G., Chen, Y.Q., Zhang Z.S., "Forecasting method for monthly natural oil production of old wells in oilfield", ACTA PETROLEI SINICA, Vol.28, No.3 (May 2007), 109-110

[8] Liu Y.K, Bi Y.B, Sui X.G, Wu X.H, "Production performance forecast of oil \& gas fields at the depletion stage", Natural gas industry, Vol.27, No.3(March 2007),100-102

[9] Baker, R.O. et al.: "Using an Analytical Decline Model to Characterize Naturally Fractured Reservoirs," paper SPE 39623 presented at the 1998 SPE/DOE Improved Oil Recovery Symposium, Tulsa, 19-22 April.

[10] Callard, J.G.: "Reservoir Performance History Matching Using Rate/Cumulative Type-Curves," paper SPE 30793 presented at the 1995 SPE Annual Technical Conference and Exhibition, Dallas, 22-25 October.

[11] Camacho-V., R. and Raghavan, R.: "Boundary-Dominated Flow in Solution-Gas-Drive Reservoirs," SPERE (November 1989) 503.

[12] Chen, H.Y. and Poston, S.W.: "Application of a Pseudo time Function to Permit Better Decline-Curve Analysis," SPEFE (September 1989) 421.

[13] Cutler, W.W. Jr.: "Estimation of Underground Reserves by Well Production Curves," Bull., USBM (1924) 228.

[14] Da P.G., Cinco-L, H., and Ramey, H.J. Jr.: "Decline Curve Analysis Using Type Curves for Two-Porosity Systems," SPEJ (June 1981) 354.

[15] Xie, C.-j. Cai, E.F. Guan, Z.L, "Oil \& Gas Development Geology", China University of Geosciences press, (September 2004) 205.

[16] Zhou, H. Guan, Z.L, "Oil Reservoir Engineering”, China University of Geosciences Press, (May 2004) 67.

[17] Arps J J. "Estimation of Primary Oil Reserves". Trans, AIME, $1956 ; 207: 182^{\sim} 186$

[18] Hubbert M K. "Energy Resources National Academy of Science",National Research Council.Washington D C,1962

[19] Faulder, D.D.: "Advanced Decline Curve Analysis in VaporDominated Geothermal Reservoirs," paper SPE 38763 presented at the1997 SPE Annual Technical Conference and Exhibition, San Antonio, Texas, 5-8 October.

[20] Fetkovich, M.J. et al.: "Decline-Curve Analysis Using Type Curves-Case Histories," SPEFE (December 1987) 637; Trans., AIME, 283.

[21] Fetkovich, M.J., Fetkovich, E.J., and Fetkovich, M.D.: "Useful Conceptsfor Decline-Curve Forecasting, Reserve Estimation, and Analysis,"SPERE (February 1996) 13. 